\title{
Mujeres y cárceles en América Latina. Perspectivas críticas y feministas
}

\author{
Elisabet Almeda Samaranch \\ Universitat de Barcelona \\ elisabet.almeda@ub.edu \\ Dino Di Nella \\ Universidad Nacional de Río Negro \\ dino.dinella@unrn.edu.ar
}

Recepción: 08-06-2016

Aceptación: 29-09-2016

\section{Resumen}

Las cárceles femeninas en América Latina constituyen una buena atalaya donde mirar las nuevas tendencias del control punitivo hacia las mujeres encarceladas en el resto del mundo. Las precarias condiciones de vida de las presas, la criminalización por drogas de las que son pobres, las discriminaciones y vulneraciones de sus derechos, en especial de las indígenas y también las resistencias a la disciplina y a la arbitrariedad carcelaria son, entre otros, algunos de los temas que se han ido analizando en las últimas tres décadas en América Latina por parte de investigadoras feministas. El objetivo del artículo es hacer una revisión y un análisis de las principales autoras y de los principales estudios feministas sobre el sistema de justicia criminal en relación con las mujeres, con especial atención al control penal y a las cárceles femeninas, para visibilizar lo que se ha escrito y así empezar a transformarlo.

Palabras clave: América Latina; mujeres; cárceles; feminismo; pobreza; drogas y familias

\section{Abstract. Women and Prisons in Latin America: Critical and Feminist Perspectives}

Women's prisons in Latin America are a good watchtower from which to observe new global trends in punitive control towards imprisoned women. The precarious living conditions of women prisoners, criminalisation of impoverished women for drugs, discrimination and violations of rights (particularly of indigenous women) and resistance to prison discipline and arbitrariness are among some of the topics that have been investigated in the past three decades by feminist researchers in Latin America. The aim of this article is to review and analyse the main feminist authors and feminist research on the criminal justice system in relation to women, with particular attention given to penal control and to female prisons in order to make visible what has been written and begin to transform it.

Keywords: Latin America; women; prisons; feminism; poverty; drugs and families 


\section{Sumario}

$\begin{aligned} \text { 1. Introducción } & \begin{array}{l}\text { 4. Criminalización de las mujeres, } \\ \text { resistencias y relaciones amorosas }\end{array} \\ \text { 2. Precursoras: análisis feministas } & \text { en contextos de encierro y opresión } \\ \text { del sistema de justicia criminal } & \text { 5. Abordajes institucionales para mejorar } \\ \text { y las mujeres en América Latina } & \text { las condiciones de vida de mujeres } \\ \text { 3. Criminalización de las mujeres y } & \text { privadas de libertad } \\ \text { políticas de guerra contra las drogas en } & \text { 6. Conclusiones } \\ \text { contextos neoliberales } & \text { Referencias bibliográficas }\end{aligned}$

\section{Introducción ${ }^{1}$}

Uno de los espacios académicos privilegiados de disputa simbólica y política del sistema patriarcal es el subsistema de control penal. El eurocentrismo criminológico y feminista está todavía muy presente en muchos análisis del sistema de justicia criminal respecto de las mujeres. Sin embargo, han ido irrumpiendo con fuerza las científicas sociales feministas de América Latina. Hace más de treinta años que, en este continente y desde perspectivas críticas y feministas, se está discutiendo, escribiendo y politizando la criminalización de las mujeres en conflicto con la ley penal y la relación que estas tienen con el sistema de justicia criminal. Conforman un conjunto extenso de trabajos sólidos, fundamentados, que deconstruyen los discursos generalizados sobre la criminalidad femenina y sus estereotipos, analizando la situación de las mujeres encarceladas y de las cárceles femeninas, así como denunciando sus discriminaciones, sus vulneraciones de derechos y las categorías de género, clase y raza que las determinan.

Pero también visualizan la temática desde una perspectiva propia de los contextos, los momentos históricos y los territorios, dando las voces a las mujeres o hablando a través de ellas, proponiendo alternativas que alteren las múltiples realidades de las transgresoras de las leyes penales en América Latina. Y, cada vez más, muchas de las investigadoras se implican en instituciones gubernamentales o en las realidades de las presas, construyendo, conjuntamente con ellas, resistencias y alternativas a la opresión y a la exclusión que, hoy por hoy, representa la cárcel, el control y el castigo a las mujeres.

No obstante, no existe un abordaje actual que caracterice íntegramente esta prolífica labor. El objetivo del presente artículo es hacer una sistematización de la producción científica latinoamericana sobre el sistema de justicia criminal en relación con las mujeres, con especial atención al control penal y a las cárceles femeninas, desde una perspectiva crítica y feminista.

1. Este articulo se ha desarrollado en el marco del proyecto europeo INCASI Network que ambos autores integran. El proyecto ha recibido financiación del Programa European Union's Horizon 2020 research and innovation programme bajo la dirección de Marie Skłodowska-Curie GA No 691004 y la coordinación de Pedro López-Roldán. El artículo refleja la opinión de los autores y el Programa no es responsable de cómo se utiliza la información que el mismo contiene. 
Para ello, se partirá de una revisión y de un análisis de las principales autoras e investigaciones críticas y feministas que han ido desarrollándose desde hace más de 35 años, sobre el sistema latinoamericano de justicia criminal en relación con las mujeres, con especial atención al control penal y a las cárceles femeninas. No pretende ser un trabajo exhaustivo que agote en sí mismo (y, a la vez, empobrezca de tal manera) el diverso y plural espectro temporal y geográfico de las producciones que abrieron las puertas a la temática en la región.

Las autoras a las que cabe referirse han sido pioneras (precursoras, continuadoras, desarrolladoras, ahondadoras) en sus países y/o continentes a la hora de estudiar a las mujeres en conflicto con la ley penal, bien porque han sido las primeras en hacerlo en el marco de su academia, bien porque muchos de sus enfoques han sido y son cuestionadores, disruptores, tanto de la criminología tradicional como de las políticas penales y penitenciarias que todavía se implementan en muchos de esos países.

Seguramente van a faltar muchas citas, referencias e investigaciones, especialmente de países poco o nada mencionados, al igual que otros enfoques críticos que están emergiendo e incluso estudios que no tengan la perspectiva feminista pero que son útiles para este análisis. Todo ello se deja para trabajos futuros que ya se reivindican desde este artículo: recensiones mayores y detalladas de todo lo que se está produciendo sobre el sistema de justicia criminal y las mujeres. En este, primero, hemos hecho una introducción al presente artículo. En segundo lugar, abordaremos los análisis feministas del sistema de justicia criminal y las mujeres en América Latina a través de las obras de seis de sus precursoras más notables durante las tres últimas décadas del siglo pasado. En tercer lugar, veremos lo que se ha ido escribiendo desde el comienzo del siglo XXI, agrupando sus producciones en diferentes ejes analíticos, y comenzando con las producciones vinculadas a la criminalización de las mujeres como consecuencia de las políticas de guerra contra las drogas en contextos neoliberales. En cuarto lugar, seguiremos con la criminalización de las mujeres y su relación con sus resistencias y sus comunicaciones amorosas en contextos de encierro y opresión. En quinto lugar, se estudiarán los abordajes institucionales que se han llevado a cabo con la finalidad de mejorar la situación y las condiciones de vida de las mujeres privadas de libertad. Finalmente, se presentan unas conclusiones generales y las referencias bibliográficas respectivas.

\section{Precursoras: análisis feministas del sistema de justicia criminal y las mujeres en América Latina}

La humanidad tercermundista con su capacidad inmensa de adaptación a la adversidad está aquí, tejiendo paradójicos vínculos a fuerza de conversaciones, risas, transacciones, millones de pequeños empujones, buen humor, angustia.

Andrea Aguirre, 2010

A la par de las perspectivas críticas de la criminología a nivel internacional, la criminología latinoamericana se ha ido desarrollando desde múltiples investi- 
gaciones y publicaciones con incidencias variadas en las políticas criminales, penales y penitenciarias del continente, pero con una clara influencia de la disciplina criminológica y de la sociología jurídica de esta región. Rosa del Olmo, Lola Aniyar de Castro, Roberto Bergalli, Juan Bustos Ramírez, Alda Facio, Eugenio Raúl Zaffaroni, Elías Neuman, Nilo Batista, Carlos Alberto Elbert, Emiro Sandoval Huertas, Vera Malaguti, entre muchos otros más, son científicos destacados en la materia.

$\mathrm{Al}$ igual que a la criminología crítica anglosajona, los iniciales marcos teóricos y de referencia de Latinoamérica que las constituyeron, en general no incorporaron a las mujeres en sus análisis.

La criminología crítica no lo ha hecho ni siquiera a nivel de texto programático general, y mucho menos se ha ocupado de áreas que en América Latina son prioritarias, como la mujer y los menores. Ignora, por ejemplo, que la mujer presenta grados de control social particulares por ser oprimida independientemente de su clase y, por tanto, no puede incluirse dentro de la criminalización tradicional. Es más, si bien se puede decir que la criminología crítica en América Latina toma en consideración la variable clase al hablar del problema del poder, ignora la variable sexo, al igual que lo ha hecho la criminología positivista. (Del Olmo, 1987: 38)

Raúl Eugenio Zaffaroni tiene un breve texto en donde analiza la ausencia de las mujeres tanto del discurso dominante en la criminología y el derecho como del discurso punitivo (Zaffaroni, 1993). Se trata de un documento al que recurrentemente se hace referencia, no obstante existir otras elaboraciones y autoras contemporáneas o posteriores que, sin quitar los méritos que se puedan atribuir a este trabajo, han aportado mayor profundidad teórica, analítica y empírica al tema.

Las dos pioneras de la crítica criminológica a las perspectivas positivistas y etiológicas en América Latina fueron Lola Aniyar de Castro y Rosa del Olmo, hacia la década de 1970. Así lo considera el propio Raúl Eugenio Zaffaroni:

Este torrente de claridad que se esparcía por todo nuestro saber y que nos llamaba a la responsabilidad frente a la propia vida de nuestros semejantes, provino de Venezuela y fue obra de dos mujeres: las profesoras Lola Aniyar de Castro y Rosa del Olmo. Sus escritos e intervenciones conmovieron a toda la criminología latinoamericana y extendieron sus efectos al penalismo, aunque éste, hasta el presente, busca refugio infructuosamente en la caverna del normativismo. (Zaffaroni, 2015: 2)

La criminóloga venezolana Lola Aniyar de Castro (1937-2015) fue fundadora del Grupo Latinoamericano de Criminología Crítica (Aniyar de Castro, 1976, 1986, 2002), además de política, profesora y abogada penalista. Aparte de ello, escribió libros de referencia sobre criminología, realizó un trabajo sobre delincuencia femenina que llevó a cabo en 1986 y que después actualizó en 2002, en donde analizaba críticamente la construcción social de las mujeres 
infractoras desde las perspectivas dominantes de la criminología (Aniyar de Castro, 1986, 2002). Cuestiona el estereotipo sexista porque no responde al perfil real de «mujer criminal» y explica cómo, desde el derecho penal venezolano, la definición de los delitos también responde a esta lógica de «la problemática de lo femenino» cuando la mujer delinque:

Las mujeres infractoras eran, pues, por rebelarse al rol social-sexual asignado, ¡las pecadoras sexuales, las brujas, las ebrias, las de vida desordenada, las desobedientes! Nada ha cambiado demasiado, como veremos, a pesar del grado de incorporación de la mujer al trabajo productivo, sólo que ahora lo vemos más sutilmente reflejado. (Aniyar de Castro, 2002: 338)

Según la autora, el estereotipo de mujer criminal todavía existe en la realidad policial, judicial y penitenciaria venezolana, y solo desde un marco conceptual con perspectiva de género puede interpretarse la situación en la que se encuentran las cárceles femeninas del país y el tratamiento que se les brinda a las mujeres encarceladas, que, a principios del 2000, no representaban más del $4,5 \%$ del total de la población presa. Citando un estudio de Aponte (2002) sobre la sección femenina de la cárcel nacional de Maracaibo, la autora desgrana las vulneraciones de derechos y las discriminaciones a las mujeres presas de esta cárcel venezolana, mayormente mujeres indígenas (wayúu) que fueron recluidas sin la interpretación obligatoria del proceso en su lengua y también extranjeras (30\%); todas ellas con menores beneficios procesales, condenadas sobre todo por delitos relacionados con las drogas, sometidas a violencias física y psicológica durante la detención; obligadas a realizar tareas y trabajos sexistas de limpieza y de manualidades y a separarse de sus hijos e hijas, con quienes van perdiendo los vínculos (Aniyar de Castro, 2002: 345-346):

El Estado debe evaluar qué prefiere; si tener una reclusa más o una familia menos, menos menores sin afecto materno, o abandonados y en peligro de convertirse también en carne de prisión. En fin de cuentas, estas mujeres lo que hacen es convalidar su rol sexual: dar familia, recursos a los niños y ancianos de los que deben responsabilizarse. Si esas no son las motivaciones de su infracción, entones la jueza debería evaluar si lo que se está castigando es la ruptura del rol. (Aniyar de Castro, 2002: 349)

Ante toda esta situación general de discriminación, propone una justicia de género para las mujeres e instaurar alternativas a la cárcel: suspensión de la pena o su sustitución por medidas alternativas a la prisión como el trabajo para la comunidad, o para la víctima, obligación de presentarse a la autoridad periódicamente, prisión de fines de semanas, asistencia a charlas o cursos educativos y formativos, y proporcionarles la posibilidad de aprender un oficio para mantener a sus hijos:

Entre tanto, a las infractoras con penas alternativas, deberían otorgárseles las condiciones de alimentación y salud, las de aprendizaje y trabajo, que podrían 
permitir unas mejores condiciones de vida, aptas para su condición de generadoras de vida. Total, ni son tantas ni tan peligrosas. (Aniyar de Castro, 2002: 350)

La trayectoria y la obra de la socióloga y criminóloga Rosa del Olmo PérezEnciso (1937-2000) debe enmarcarse en la tradición de la criminología crítica latinoamericana y la criminología feminista en esta región (Del Olmo, 1981, 1987, 1988, 1989, 1991, 1998a y 1998b). Nacida en Barcelona, con madre y padre decididos luchadores republicanos, se exilió al final de la Guerra Civil española con su madre, poetisa andaluza, en México, Cuba y, finalmente, Venezuela, su país de adopción. Fue durante toda su vida una activa feminista, inagotable luchadora social y una de las criminólogas más versadas en el análisis sociopolítico y económico sobre el tráfico de drogas. A este tema dedicó mucha de su vasta obra, publicando libros y varios artículos en la revista Nueva Sociedad (Del Olmo, 1989, 1991, entre otros), en la que tiene uno específico sobre mujeres. Como indica Castillo, en su interesante y ameno artículo de repaso de los temas de género en la obra de Rosa del Olmo (2008: 250), fue justo esta revista la que, en el año 1987, convocó el III Certamen Latinoamericano de Ensayo Político sobre el tema "Ser mujer en América Latina» y Del Olmo fue la autora de una de los textos ganadores, «La crisis económica y la criminalización de la mujer latinoamericana», que después la revista publicó bajo el título «Drogas y criminalización de la mujer» (Del Olmo, 1988). En la investigación, se plantea que, en momentos de crisis económica como la que atravesaban muchos países de América Latina a finales de los años ochenta, la mujer latinoamericana se ve obligada a entrar en el negocio ilegal de las drogas, por necesidades económicas, a causa del desempleo vigente y como estrategia de supervivencia. Siempre en peores condiciones que los hombres, discriminadas en sociedades patriarcales que las subordinan, también estarán marginadas en el negocio de las sustancias ilegales, donde desempeñarán papeles limitados y secundarios — «oficios del hogar», como denomina Del Olmo- en la casa donde se prepara, se almacena o se vende la mercancía. O transportándola en su cuerpo, por el continente americano, a cambio de muy poca remuneración por el riesgo que comporta. Riesgo todavía mucho mayor, como comentábamos anteriormente, si las mujeres atraviesan el océano con la droga en sus cuerpos o en sus valijas y son detenidas en los aeropuertos de Barajas o del Prat: las latinoamericanas encarceladas en Europa por ser «mulas o correos» (Ribas, Almeda y Bodelón, 2005).

Del Olmo examina los datos socioeconómicos de la criminalidad y los procesos de criminalización por drogas, que, si bien las saca del desempleo, las encierra también en la cárcel y las estigmatiza severamente como delincuentes (Del Olmo, 1988). A partir de un estudio descriptivo-exploratorio de 181 expedientes de mujeres detenidas por drogas en Venezuela, observa que esas mujeres, en estos primeros eslabones de la cadena del narcotráfico, ocupan roles subalternos: preparan la droga, la venden, la esconden y la introducen en sus cuerpos (en la vagina o en el estómago), y actúan de correos, de pequeñas expendedoras o vendedoras al menudeo, así como de transportistas locales, 
nacionales e internacionales que están a las órdenes masculinas y que mayormente reciben las migajas de ese lucrativo negocio masculinizado en sus autoridades y en sus formas. Años más tarde, en 1996, Del Olmo retomará el tema en una reunión del grupo de Consulta sobre el impacto del abuso de drogas en la mujer y la familia (convocada, entre otras entidades, por la Organización de los Estados Americanos). Entre otras cuestiones, se tratará como punto específico la reclusión de mujeres por delitos de drogas, hecho que «redimensionó el alcance del proyecto original más allá de las consideraciones sobre la salud y la familia al permitir reflexiones de tipo criminológico» (Del Olmo, 1998a: 5). La autora destaca la poca o nula importancia que las investigaciones sobre abuso de drogas o tráfico ilícito otorgan a los análisis de género, a excepción de algunos estudios feministas o gubernamentales de los Estados Unidos, el Canadá o el Reino Unido.

Los patrones de consumo y los perfiles de consumidoras son distintos y propios de las mujeres; por ello considera necesario estudiarlos de manera independiente y específica, especialmente cuando se las criminaliza. Así, vuelve a plantear uno de los temas clave para entender la realidad de las mujeres en las cárceles, así como la criminalización de sus comportamientos «ilegales». Fiel a los preceptos de la criminología crítica, recalca la importancia de los análisis criminológicos que hoy denominaríamos «situados» (aunque ella no utilizará esa palabra). Ya en los años noventa, criticaba aquellos análisis latinoamericanos basados en teorías feministas sobre la criminalidad femenina originadas en países europeos o de Norteamérica (Del Olmo, 1998a). Porque, entre otras cuestiones, no tenían en cuenta factores estructurales o socioeconómicos propios de las sociedades latinoamericanas. Para esta autora, hay que comprender el tema desde una perspectiva regional, partiendo de la consolidación de las instituciones sociales y las desigualdades de género, con claras diferencias en el acceso a los derechos laborales, educativos y sanitarios. En este sentido, deberían incorporarse algunas particularidades estructurales, como la importancia de la mujer como figura protagónica en la familia, por la predominancia de los hogares matricentrados, de jefas de hogar o la alta presencia femenina en la economía informal o sumergida.

Finalmente, en el año 1997, Del Olmo organiza un seminario taller titulado "La criminalidad y la criminalización de la mujer de la Región Andina», con apoyo de diversas entidades y con las mejores especialistas de Venezuela y de varios países de América Latina. Por primera vez de manera conjunta en América Latina y desde una perspectiva de género, estos problemas se abordan de manera promisoria. Del evento, ha quedado un libro clave sobre el tema, que recoge los aportes de todas ellas (Del Olmo, 1998b). Hay artículos de México (Azaola, 1998); Bolivia (Achá, 1998) y Colombia (Dorado, 1998), entre muchos otros, a los que precede uno de Rosa del Olmo. En él, analiza brevemente las distintas teorías de la criminalidad femenina, cuestionando una vez más las explicaciones positivistas y estereotipadas de los primeros criminólogos de finales del siglo xix. Y se propone, además, crear una red de expertos y de expertas para estudiar las razones del incremento de las mujeres 
encarceladas por delitos de drogas en todos los países de la región. El encuentro fue un hito en la investigación de este ámbito, ya que se sistematizó de manera excelente las distintas caras que podrían trabajarse, impulsando muchas de las investigaciones que se desarrollaron en la década siguiente.

Otro aporte que merece ser destacado especialmente es el de la mexicana Marcela Lagarde, activista, antropóloga, académica y referente del feminismo en América Latina. En el año 1990, publicó su excelente y extenso libro Los cautiverios de las mujeres: Madresposas, monjas, putas, presas y locas, reeditado por cuarta vez en 2005, a partir del trabajo de su tesis doctoral en la Universidad Nacional Autónoma de México. Un libro clave en la antropología feminista, en cuyo capítulo XII — 40 páginas de un total de 900 —, versa específicamente sobre presas. Con ellas, habló, convivió y dialogó en cárceles y en centros de detención, para su investigación etnográfica de "estancia con las mujeres», como ella denomina a su metodología.

Lagarde nos dirá que las presas por delitos «[...] concretan social e individualmente las prisiones de todas [...] de tal manera que el análisis de las presas da luz sobre las prisiones diversas en que viven todas las mujeres» (Lagarde, 1990: 642). Nada más y nada menos. Porque todas somos prisioneras y cautivas, sujetas a los cautiverios de nuestra condición genérica de mujeres. Cautivas y cautivadas en el mundo patriarcal. Se trata de «descifrar la medida y permitir deconstruir los cautiverios, y en saber si esos hechos conducen hacia la construcción de nuevas identidades, de alternativas sociales, culturales y políticas» (Lagarde, 1990: 861).

Es muy crítica con los enfoques dominantes que patologizan a las mujeres presas y que ven como enfermas a las infractoras a la ley penal, que reducen su comportamiento a problemas individuales y que parten de un determinismo entre sexo y delito: «No hay tal, la delincuencia no tiene génesis ni causalidad sexual, no deriva de la biología, sino de la sociedad y la cultura» (Lagarde, 1990: 644).

Sostiene que la participación de las mujeres en el delito es doble: de víctimas y de delincuentes. Víctimas, en mayor medida, por la gran cantidad de mujeres que padecen violencia machista y delitos cometidos contra ellas, y delincuentes, en menor medida, porque la gran mayoría de delitos son cometidos por hombres. Las mujeres sobre todo cometen delitos contra la propiedad, robos y hurtos, y contra la salud, que están muchas veces en relación con delitos de drogas vinculados a «sus hombres», con quien delinquen y después son detenidas. Así, en México, país de paso de las redes de narcotráfico de Sudamérica a Estados Unidos, muchas mujeres amantes de narcotraficantes son detenidas como "burros» por llevar droga en el cuerpo. A parte, también trafican en las cárceles, introduciendo drogas amparadas en las visitas conyugales para ver a sus maridos o amantes. Después, en muchos casos, son detenidas por ello y encarceladas con condenas contra la salud. Se convierten en "vehículo del tráfico», cuerpos objeto, cuya vagina sirve de vehículo para introducir las drogas requeridas por los presos, que tienen prohibido su uso (Lagarde, 1990: 654-655). 
El cautiverio de todas las mujeres se expresa en «la falta de libertad, concebida ésta última como el protagonismo de los sujetos sociales en la historia, y de las particulares en la sociedad y en la cultura. En tanto que cautiva, la mujer se encuentra privada de libertad» (Lagarde, 1990: 37). Si, además, se la condena a una pena privativa de libertad, sobre ella recaerá todo el peso patriarcal de la ley penal y penitenciaria:

Aun cuando para ambos géneros la prisión tiene como consecuencia además del castigo, el desarraigo y la separación de su mundo, para las mujeres es mucho mayor, ya que la mayoría son abandonadas por su parientes en la cárcel. Ser delincuentes y haber estado en prisión son, también, estigmas mayores para las mujeres. (Lagarde, 1990: 676)

Por el papel central que tiene la maternidad en la definición de las mujeres, la suspensión de su capacidad de custodia y tutelaje o, por el contrario, el hecho de que hasta en la cárcel deba cuidar de sus hijos, hacen la vida en prisión genéricamente opresiva para las mujeres y para su prole. (Lagarde, 1990: 677)

La cárcel es el ámbito del odio social a las mujeres transgresoras. La violencia carcelaria es el contenido reglamentado de la institucionalidad coercitiva, y se desarrolla también en la interacción del cuerpo represivo y de custodia. (Lagarde, 1990: 680)

Así, la estancia en la cárcel es a la vez explotación y castigo económico, que se complementan con los pagos subterráneos que hacen las presas para tener acceso a bienes y servicios mínimos, y para pagar sobornos y evitar sobrecastigos, para lograr que sus papeles aparezcan o para que el abogado defensor de veras las defienda [...] Abandonadas, las presas, la mayoría sin visitas familiares, siguen esperando que alguien venga a verlas: «abandonadas debido a su encarcelamiento, $\mathrm{y}$ a su transformación pública e inocultable en malas mujeres». (Lagarde, 1990: 684)

Otra de las referentes en el tema que estamos analizando es Elena Azaola, también mexicana, antropóloga y psicoanalista, investigadora del Centro de Investigaciones y Estudios Superior en Antropología Social. Es pionera en su país y a nivel internacional por sus estudios sobre criminalidad y mujeres, instituciones carcelarias y derechos humanos, maltrato y explotación infantil. Ha publicado trabajos comparativos entre hombres y mujeres sentenciados por delitos de homicidio para mostrar las discriminaciones del sistema de justicia criminal hacia las mujeres, así como estudios sobre las cárceles femeninas con análisis cuantitativos, cualitativos y etnográficos, en los que visibiliza las penosas y durísimas realidades penitenciarias que viven las presas. Para ello, les da la palabra a ellas, analizando las condiciones de vida, los programas, las políticas y denunciando las violaciones constantes de sus derechos, recomendando propuestas para transformar la situación actual y poner en práctica penas alternativas a la prisión (Azaola, 1995, 1996a, 1996b, 1997, 1998, 2002 y 2005; Azaola y José Yacamán, 1996). 
Azaola documenta la ausencia de investigaciones sobre las cárceles de mujeres en México, las presas son "las mujeres olvidadas», y también la falta de perspectiva de género en las investigaciones sobre sistema penal y penitenciario en general, en las que todavía son dominantes las perspectivas biologista y/o psicologista que a la vez sustentan las políticas penales y penitenciarias mexicanas. Sostiene, desde una perspectiva de género, la triple discriminación de las mujeres encarceladas, la que deriva de su propia condición femenina, la que les impone su situación de prisioneras y las que es común a todos los grupos pobres y desposeídos del país. En su extensa investigación con perspectiva de género sobre las mujeres en las prisiones de México, efectuada a principios de la década de 1990 con José Yacamán, pretende «responder a intereses de grupos aparentemente disímbolos: funcionarios, especialistas y mujeres reclusas, de tal manera que se lograra formular una proyecto que articulara y respondiera a las necesidades y preocupaciones de estos protagonistas [...] una investigación de carácter interdisciplinario, fundamentalmente cualitativa (Azaola y José Yacamán, 1996: 17). Objetivos que va a seguir persiguiendo en todas sus investigaciones sobre el tema, en las que demuestra cómo el sistema penitenciario toma como modelo al varón y dicta las normas a partir de sus necesidades, siendo la mujer una especie de apéndice que se agrega a dicho modelo. Al ser ellas una pequeña proporción del conjunto de «delincuentes» que no llega al $4 \%$, en el caso de México, las que ingresan en el circuito de la justicia deberán enfrentar un sistema compuesto por normas, discursos, prácticas y cárceles pensadas y diseñadas para varones. De los establecimientos penitenciarios que hay en el país, en más de la mitad existían - y existen todavía - un lugar, una pequeña sección, un rincón o una celda en donde se ubican a las mujeres sentenciadas o en proceso en México (Azaola, 1995: 37).

En estudios posteriores, demuestra que el número de mujeres ha crecido más de tres veces que el de los hombres en el período 1994-2004 (Azaola, 2005). A principios de los años noventa, examinó la gran mayoría de estos encierros femeninos, con estudios minuciosos de muchas de las distintas penitenciarías y Ceresos (Centros de readaptación social). Analizó su ubicación, arquitectura, condiciones de vida, trabajo, educación, otorgamiento de beneficios, talleres, entre otros muchos aspectos que definen la vida carcelaria de las mujeres. También, a través de las visitas a los centros, cuestionarios, entrevistas, estudio de datos y testimonios de mujeres, analiza su perfil social y penal-penitenciario. Como resultados destacados, se subraya la falta de centros exclusivos para mujeres, a excepción de unos pocos llamados de «readaptación social», lo que comporta muchas desventajas para ellas, porque siempre se priorizan las demandas, los espacios, los servicios y la atención de los hombres, y las de las mujeres, "como siempre son pocas», están postergadas indefinidamente (Azaola y José Yacamán, 1996). Asimismo, se repiten las historias de mujeres pobres, con hijos e hijas y mayormente presas contra la salud y por delitos de drogas, que cada vez aumenta más (en el año 2005, era el mayoritario, con un 50\% de todos los casos).

Otros temas que sobresalen en las investigaciones de Azaola son la situación de los hijos e hijas de las presas (las condiciones que enfrentan si están encarce- 
lados con ellas) y el incremento de mujeres indígenas encarceladas en México, ambas circunstancias en clara indefensión jurídica, sumando así, a la discriminación por clase y género, la étnica (Azaola, 2008 y 1996b). Asimismo, desde el sistema carcelario, se prescribe masiva e indiferenciadamente a estas mismas mujeres encarceladas por delitos de drogas, mayormente no consumidoras de las que transportan, sustancias altamente adictivas como son los «tranquilizantes». Así podrán sobrellevar, «adormercidas», arreflexivamente, su difícil y dolorosa realidad penitenciaria (Azaola, 1998). Y también se destaca el análisis de la violencia como una constante en la vida de las mujeres presas, tanto en el seno de sus familias, en donde en muchos casos han sufrido violencia machista, como por parte de las fuerzas de seguridad en los centros de detención, con torturas, abusos sexuales, malos tratos, amenazas e insultos cuando se las interroga. En el interior de las cárceles de México, muchas mujeres realizan trabajos extras. No hay un solo penal donde las actividades cotidianas intramuros no estén relacionadas con trabajos estereotipados y relegados al rol doméstico de la mujer en las condiciones y con los abusos, las violencias y las extorsiones que el sistema permanentemente les provoca: el aseo, la costura, la cocina, el lavado de ropa, la limpieza de baños (de ellas y de los hombres), los trabajos manuales y de productos como bolsas tejidas y muñecas de peluche o prestar servicios sexuales (Azaola, 1995: 43).

En particular, Azaola se interesó por estudiar, a partir del alto índice de muertes por violencia en México, el delito de homicidio como un delito privilegiado para desvelar las profundas diferencias de género existentes, tanto en las modalidades de actos delictivos que cometen como en el trato que reciben de la justicia (Azaola, 1996a y 1997). La mayor parte de las veces, ellas dan muerte a familiares, mientras que los hombres lo hacen a alguna persona ajena al núcleo familiar. Y la justicia es mucho más severa con las mujeres, con condenas de privación de libertad por un mismo delito un $25 \%$ más largas que las de los varones. El denominador común de las historias de vida relatadas por las mujeres es la marginación sufrida antes y después de ingresar en la prisión, en donde, entre otros factores, también cuenta «el delito de ser mujer», palabras que dan el título a uno de los libros de Azaola (1997).

Por último, aunque - como ya prevenimos - no podemos profundizar en todas ellas, mencionamos a la criminóloga y abogada chilena Carmen Antony García. Si bien tuvo participación en el ya nombrado encuentro de 1997 organizado por Del Olmo, es más contemporáneamente (año 2000) que Antony hizo uno de los grandes aportes a la temática, con un extenso y minucioso estudio comparado sobre las cárceles de mujeres en muchos países de América Latina. Como ella misma afirma, lo hizo desde una perspectiva de género, clave para poder analizar a fondo y sin prejuicios el tema y poder implementar políticas penitencias que respeten los derechos humanos de las mujeres presas. Antony va examinando distintos países de la región y diversos aspectos de la cotidianidad penitenciaria, así como de las políticas intramuros, con recomendaciones finales de cambio radicales y de medidas alternativas a la situación actual. Atención especial dedica a las mujeres que están confinadas con sus 
hijos e hijas, los efectos sobre ellos y ellas, a las presas políticas y a las que están sentenciadas por delitos de drogas (Antony, 2001). Antony continuará con sus estudios sobre las cárceles de mujeres con varias publicaciones y citando un esbozo del resumen de la última de ellas, donde quedan bien reflejadas algunas de sus conclusiones:

La situación de las cárceles femeninas es dramática. No solo porque las mujeres detenidas sufren el estigma de romper con el rol de esposas sumisas y madres presentes que les asigna la sociedad, sino también por la falta de leyes y políticas adecuadas para abordar problemas como el de las madres lactantes o los hijos de las mujeres encarceladas. Esto se suma a otras cuestiones, como la violencia sexual y el hacinamiento producto del aumento de la población penitenciaria femenina, generalmente por delitos relacionados con el microtráfico de drogas [...] para resolver estos graves problemas, es necesario incluir un enfoque de género en las políticas penales y penitenciarias. (Antony, 2007: 73)

En todas las investigaciones sobre cárceles femeninas mencionadas — que son casi las únicas investigaciones existentes sobre cárceles de mujeres en esta época, a excepción de algunas publicadas por las propias administraciones penales o penitenciarias-, se repiten los argumentos, las ideas contrastables y los resultados de análisis empíricos que venimos describiendo. El sistema penitenciario se empeña en reforzar la construcción diferenciada y asimétrica por género. «Mano dura» del Estado y de la sociedad para criminalizar al eslabón más débil de la cadena. Escarmiento a las mujeres.

\section{Criminalización de las mujeres y políticas de guerra contra las drogas en contextos neoliberales}

Recordemos que cuando se encarcela a una mujer, no sufre un individuo sino una red social completa. En el siglo xxi, la cacería de brujas continúa: se siguen atrapando mujeres excluidas.

Lisset Coba, 2015

Las mujeres encarceladas en América Latina son una parte muy pequeña del total de población reclusa. Representan un promedio del 5\% del total, con extremos en Ecuador y Argentina de casi el 10\% (en Argentina, en el caso de las cárceles federales) y de Bolivia, con el 20\% (Daroqui et al., 2006: 52; Torres, 2008: 9, respectivamente). Las investigadoras feministas ya han señalado muchas veces que esta baja estadística ha sido a menudo la excusa que ha justificado el olvido de las mujeres presas en las políticas penales y penitenciarias, como también en las teorías y en los estudios criminológicos. No obstante, como argumentan Nari y Fabre, ello tiene otros alcances: «una parte importante de la lógica de la violencia institucional que se manifiesta especialmente en las formas en que las mujeres son castigadas, no aparece explicada» (2000: 12). Entre estas explicaciones, cabe destacar que, a partir del nuevo 
siglo, se da un proceso de criminalización de las mujeres por delitos de drogas que comporta un desorbitado crecimiento de las tasas de encarcelamiento femenino en toda América Latina. En solo 6 años (entre 2006 y 2011), la población reclusa femenina casi se duplicó (pasó de 40.000 a más de 74.000 mujeres) y sigue creciendo en la actualidad. La gran mayoría son encarceladas por delitos relacionados con la comercialización o el tráfico y el contrabando de drogas. En Brasil, un 60\% de las mujeres presas lo estan por delitos vinculados a las sustancias estupefacientes. En Venezuela, el 70\%. En México, las cárceles federales o prisiones fronterizas son entre el 75\% y el 80\% (Giacomello, 2013: 12-13). En Ecuador, son casi un 80\% (Torres, 2008: 9). En Costa Rica, un 64\% (Palma Campos, 2011: 246). Y en Argentina, en las cárceles federales, son casi un $70 \%$, que llegaba al $90 \%$ de los delitos cuando eran mujeres extranjeras, que representaba aproximadamente el $50 \%$ del total de mujeres presas en estos centros penitenciarios (CELS, 2011: 29-30).

Una vez más, ahora en palabras de Torres (2008: 8): «Los procesos de criminalización de las mujeres están histórica y contextualmente situados» (ver también Almeda, 2002). Contextualizando, entonces, hay que ubicar la criminalización de las mujeres en América Latina en el marco de la "guerra contra las drogas», emprendida primero desde Estados Unidos, con enfoques prohibicionistas del tema, y seguida también por las políticas antidrogas desarrolladas en los países latinoamericanos desde los años noventa. Para varias autoras, el crecimiento de las tasas de encarcelamiento femenino se debe principalmente a esta "guerra", que pregonaba una fuerte persecución de las infracciones relacionadas con las drogas y, en consecuencia, la sanción de leyes de estupefacientes o su contrabando más punitivas. Así se señala para algunos países europeos, en especial el Reino de España (Almeda, Di Nella y Navarro, 2012). También en el estudio del Centro de Estudios Legales y Sociales (CELS) para el caso de Argentina. Y cabría ampliar la misma conclusión para América Latina en general.

En efecto, el incremento de las penas en torno a la tenencia, el tráfico y la comercialización de estupefacientes que las leyes preconizan significó, y sigue significando todavía, un proceso de criminalización diferencial entre los sexos, que se ceba especialmente en contra de las mujeres (CELS, 2011: 24-25). Ellas son claramente las perjudicadas y esta política contra las drogas impacta sobremanera sobre sus personas, encerrándolas en las cárceles si los delitos son de trafico o contrabando, con condenas de entre ocho y doce años en el caso ecuatoriano. Se perdió, en estos casos, la proporcionalidad de la pena. Gran parte de las «mulas» tiene por ello su primer ingreso en la cárcel, y muchas son extranjeras, mayormente de otros países de América Latina. Pocos son los grandes narcotraficantes detenidos. Ellas son el «chivo expiatorio» que justifica la política antidroga: las mujeres encarceladas, «pequeñas expendedoras o vehículo de carga que transporta las sustancias ilícitas son objeto de intercambio en las alianzas masculinas clandestinas» (Coba, 2004:19).

Ahora bien, las políticas "contra las drogas» en contextos neoliberales presentan algunas particularidades que también han sido abordadas desde la 
región. En efecto, las políticas «contra las drogas» confluirán con la feminización de la pobreza y el altísimo incremento del número de mujeres encarceladas y, a la vez, con las crisis de la producción campesina. Los procesos de descampesinización, la masificación del comercio informal y el empobrecimiento urbano arrojarán a las calles a mujeres pobres insertándolas en redes ilegales y al pequeño y mediano tráfico de drogas: «las más vulneradas de la escala social se llegan a relacionar de manera íntima con las fuerzas que ejercen la posibilidad de violencia física legítima del Estado» (Coba, 2015: 176).

Wacquant (2004) ya analizaba a fondo el castigo a los pobres durante el neoliberalismo. El Estado no se debilita, sino que se reestructura, transformando las políticas de bienestar social en políticas disciplinarias de control punitivo de la población. Las fronteras geopolíticas se rompen con los delitos vinculados a las drogas. El narcotráfico teje complejas redes y jerarquías sociales en las que los trabajos más precarios y los puestos más bajos son destinados a las mujeres latinoamericanas, que quedarán expuestas a un mayor control punitivo. Desigualdad global y desigualdad penal. Las mujeres en los márgenes, como último eslabón de la cadena internacional del tráfico de drogas:

Más que una sustancia psicotrópica, la droga es un camino de acceso a la independencia económica femenina, pero al mismo tiempo, traslada al mundo de la clandestinidad los roles domésticos de madres, esposas, cómplices, jefas de hogar sin reconocimiento público. El narcotráfico es un sistema de intercambio, moneda que atraviesa distintas clases y sectores sociales; conecta las grandes mafias internacionales con las pequeñas delincuentes comunes; comunica las distintas actividades del mundo de lo ilícito. Es posibilidad de apuesta, ganancia y sobrevivencia; guarda la matriz neoliberal de un desarrollo desigual. (Coba, 2004: 19-20)

Azaola complementa este abordaje en su última investigación sobre cárceles femeninas en su país, afirmando que ha sido el tipo de resistencias a las políticas contra las drogas desarrolladas en México lo que ha incrementado las tasas de mujeres presas, especialmente de mujeres indígenas (Azaola, 2014). En los años noventa, las mujeres presas constituían un 3\% del total, pero, a principios del siglo XXI, aumentaron a más del $5 \%$. La gran mayoría están condenadas por delitos de drogas y, en relación con los últimos años, es el delito que más aumentó en este colectivo, que es el más vulnerable de las mujeres condenadas y el más invisibilizado de todos. A la discriminación por género, se añade la discriminación por etnia, que ya se había apuntado también en otras investigaciones anglosajonas, pero que la autora empieza a poner de relieve en América Latina. Mujeres indígenas que, por el analfabetismo, por sus idiomas propios, por la falta de información y apoyo y por la pobreza y la exclusión que sufren muchas de ellas, reciben explotación y maltrato constante, hasta el punto de torturarlas para que confiesen delitos que no han cometido e incomunicarlas en procesos de dudosa credibilidad (Azaola, 1996b y 2008). De hecho, la indefensión jurídica de muchas de las presas, especialmente indígenas, es otra cuestión que Azaola apunta como discriminatoria hacia las condenadas. Tanto en 
relación con la etapa del juicio como también a lo largo de la condena, destaca la extorsión por parte de abogados y abogadas particulares y el desinterés en el seguimiento de los casos por parte de estos y también de defensores públicos de oficio que no cumplen con sus visitas reglamentarias, con lo que todo contribuye a una mayor discriminación de las mujeres para acceder a la justicia y al derecho de tener una defensa penal con garantías mínimas (Azaola, 2005).

Asimismo, el excelente trabajo de Hernández (2013) también focaliza sobre el colectivo de mujeres indígenas presas en México; concretamente, en las cárceles de Puebla y Morelos. Lo hace en el marco del libro, editado junto con otras colegas del CIESAS, titulado Justicias indigenas y Estado, en donde se aborda la transformación de la relación del Estado con los pueblos indígenas por la disputa de sus derechos ancestrales y la justicia. Las mujeres indígenas sufren todo tipo de discriminaciones de género, clase y raza. Son sentenciadas y condenadas entre 10 y 15 años de cárcel por delitos no violentos relacionados con el pequeño comercio de drogas, la mayoría sin antecedentes penales, con amplias responsabilidades familiares y abocadas previamente a la extrema pobreza (Hernández, 2013). Según Hernández, en el caso de los pueblos indígenas en México, las reformas neoliberales no solo han profundizado su marginación obligándolos a migrar hacia el norte y, en muchos casos, a buscar en la siembra o en la transportación de substancias ilícitas una forma de supervivencia, sino que:

[...] paralelamente han creado una «alternativa» para controlar y explotar económicamente a este excedente laboral que el sistema deshecha mediante el desarrollo del Complejo Industrial Penitenciario, y de un aparato legal y jurídico que facilita el encarcelamiento y la explotación de los sectores más pobres de la sociedad. (Hernández, 2013: 328)

En el marco de la investigación ya mencionada, Hernández refleja claramente, con testimonios de mujeres indígenas presas, que son ellas las que han sufrido de manera más aguda las consecuencias de todas estas políticas. Mayormente presas por su participación en el narcomenudeo, ellas son básicamente las responsables de la economía familiar, las que enfrentan los impactos de la militarización de las regiones indígenas y de la guerra contra el narcotráfico y, a la violencia sexual y doméstica que sigue marcando la vida en las comunidades indígenas, se ha aunado ahora, además, la violencia policiaca y militar (Hernández, 2013: 329).

En cualquier caso, sea por las políticas de "guerra» contra las drogas, o por su formulación en contextos de implantación de procesos neoliberales, o sea por las discriminaciones y los sometimientos étnicos culturales respecto de sus formas de resistencia, lo que queda claro es la necesidad — tal como argumenta Hernández- de una perspectiva interseccional que analice la criminalización de las mujeres teniendo en cuenta las categorías de discriminación socialmente construidas, como clase, género y raza, que interactúan simultáneamente configurando contextos de desigualdad social y jurídica. 
Es en este sentido que Hernández propone recuperar las propuestas teóricas de feministas afroamericanas como Angela Davis (1981), Patricia Hill (1990, una excelente obra sobre el pensamiento feminista negro) o Margaret Andersen y la misma Hill (1992, Race, Class and Gender: An Anthology, el conocido y extenso libro manual docente, de 500 páginas, que ya va por la novena edición). En este último, las editoras van añadiendo temas y contribuciones, reactualizando reflexiones y proponiendo la perspectiva interseccional: «race, class and gender as embedded in the structure of society [...] they are structures of group opportunity, power and privilege» (Hernández, 2013: XIV). En efecto, son los sistemas de opresión de clase, género y raza que se constituyen mutuamente y que marcan el proceso de criminalización de las mujeres pobres indígenas (Hernández, 2013: 318). Capitalismo, patriarcado y racismo; tres ejes clave de la opresión de las mujeres presas que determinan su posición social subalterna en las sociedades de América Latina.

Sin duda, varios de los estudios sobre las mujeres presas en cárceles latinoamericanas así lo reflejan. Desde los enfoques más generales sobre la situación en la región de Giacomello (2013) o los de Wolff y Berbich (2010) sobre Brasil, a los estudios de caso en ciertas cárceles, como la del Buen Pastor en Costa Rica (Palma Campos, 2011), el centro penitenciario de la región andina en Venezuela (Salazar, 2007) o la cárcel de El Inca en Ecuador (Torres, 2008). En este último estudio, la antropóloga Andreína Torres ahonda en las experiencias de mujeres que se involucran en el tráfico internacional de drogas. Siguiendo algunos de los análisis de Lagarde, la autora quiere demostrar que muchas veces las que violan la ley, en realidad lo hacen adhiriéndose o apelando a su condición genérica. Considera que, en el caso de las mulas:

[...] es en la plena absorción de la normativa social (donde el género, la clase y la raza entran en juego) y no en la trasgresión de la misma que se puede explicar su situación actual y su incursión en el delito. (Torres, 2008: 27)

La autora trabaja el peso que aún tienen las identidades tradicionales de género, a pesar de la agencia — siempre limitada - de las mujeres que se insertan en el mercado internacional de las drogas en sus operaciones más vulnerables y "prescindibles». Observa que las motivaciones económicas de estas mujeres son muchas veces el único factor que esgrimen para explicar las razones por las que se involucran en el tráfico de estupefacientes. Especialmente, las que son madres lo harían para proveer a sus hogares, es decir, para cumplir plenamente un rol que les ha sido asignado social y culturalmente. Para Torres, el género, la clase y la etnicidad van definiendo experiencias particulares de estas mujeres, a través de los nexos que se establecen en las relaciones de pareja y del amor. El «amor romántico» surge muchas veces como una posible explicación de la experiencia vivida y como un factor que interviene en la constitución de identidades de género (Torres, 2008: 183-184).

Sin embargo, cabría considerar también que las «mulas» se asumen como transgresoras, al romper con los suplicios y las formas más resignadas que tie- 
nen las que no «delinquen», para aguantar así, pasivamente, el sufrimiento y el padecimiento que experimentan muchas de ellas en sus trayectorias vitales. En este sentido, las infractoras a la ley penal cumplen parte de los roles del patriarcado en la paradojal situación de estar transgrediendo socialmente otra parte de las pautas de conducta que se les asigna para cumplirlos. Adquieren, así, toda su relevancia los estudios que se han desarrollado para comprender las formas de resistencias y las elaboraciones en torno a las relaciones amorosas de las mujeres en contextos de opresión.

\section{Criminalización de las mujeres, resistencias y relaciones amorosas en contextos de encierro y opresión}

Muchas, rabiosas, creadoras, rebeldes, han dicho basta, han dicho igualdad, han dicho diferencia, han dicho autonomía, han dicho mi cuerpo es mío, han dicho soy una mujer dándome a luz.

Andrea Aguirre, 2010

No suelen explicarse las resistencias de las mujeres encarceladas. Una excepción son los estudios ecuatorianos sobre la situación de las cárceles femeninas en el país que, especialmente, analizan las formas de resistencia y lucha de las mujeres encarceladas. Son las excelentes investigaciones de Lisset Coba (2001, 2004, 2015), Andrea Aguirre Salas (2010) y del colectivo Mujeres de Frente (2004, 2006). En el marco de un ciclo de protestas carcelarias en el país, la antropóloga Lisset Coba realizó una minuciosa e intensa investigación y experiencia etnográfica sobre el motín carcelario realizado por las internas en marzo de 2004 en la cárcel de El Inca, Quito (el penal femenino más importante del país hasta fines de 2014). El punto de partida era la situación particular de las mujeres en prisión, pero articulando la dimensión política con la dimensión afectiva y abordando las relaciones de amor, poder y subordinación entre los géneros, Coba se preguntaba:

Las mujeres prisioneras son las contaminadas, las pecadoras del mundo, son sujetos sujetados de la ley y a la vez, se hallan fuera de ella. La cárcel es el infierno laico, el efecto del poder maximizado. ¿Con qué moral, con qué ética reclaman las ilegales, si han cometido las peores atrocidades? Las delincuentes suplican perdón, se les conceda el estatus de humanas. ¿Cuál es la importancia de su lucha? ¿Son los motines carcelarios sólo resultado de la oportunidad política o su dimensión se amplía a la vida misma dentro del encierro? ¿Cuál es el rol del amor como valor fundamental en la constitución de los sujetos encarcelados? ¿Cuál es la importancia del universo simbólico de lo masculino al interior de una prisión femenina? ¿Cómo se relacionan Eros y poder bajo estas condiciones? (Coba, 2001: 5)

La cárcel, espacio también de resistencia:

La cárcel es el lugar de las rutinas del cuerpo en el tiempo y en el espacio, paulatinamente va modificando el Yo, conformando el espesor social de los sujetos. 
No obstante el sometimiento, existen archipiélagos de resistencia, donde se establecen amistades, solidaridades, amores, lazos personales de organización que prestan movilidad histórica al presidio, que disputan los poderes institucionalizados por el Estado y la cultura. Las rutinas diarias son irrumpidas por rituales de ruptura que chocan, desequilibran, se interponen, atropellan la cotidianidad. El despotismo legitimado es una invitación a la revuelta. (Coba, 2004: 22-23)

En el motín de mujeres de El Inca se constituyó el colectivo Mujeres de Frente, externas e internas en la cárcel de mujeres de Quito, «como un diálogo entre mujeres diversas y desiguales: unas signadas como delincuentes y otras distinguidas como ciudadanas" (Coba, 2015: XV). Un colectivo de autoconciencia feminista, coinvestigación feminista y acción en y desde la cárcel de mujeres de Quito en el Inca:

Las palabras de mujeres presas que agrietaban los prejuiciados reportajes noticiosos durante aquellos motines carcelarios, interpelaron a un puñado de mujeres no encarceladas que decidimos cooperar con cierta defensa de las mujeres presas amenazadas por los cuerpos especiales de la policía y abrir algunos canales de comunicación desde adentro hacia afuera de la cárcel [...] Al terminar los motines, las de afuera entramos como visita, nos conocimos, y juntas decidimos emprender un trabajo colectivo entre mujeres encarceladas y no encarceladas [...] Somos un enamoramiento, un juego de bisagras, contra la resignación y el silencio de cada una, de todas nosotras y de todos; compartimos historias de sexismo, racismo, empobrecimiento, violencia sistémica y sistemática, fuerza y resistencia creadora; somos el aprendizaje en la convivencia cotidiana, en la escucha atenta, en la confianza que se reconstruye, conmoción irresistible, cuidado recíproco de unas por otras, decisión de contribuir a la transformación de este mundo. (Aguirre, 2010: 8-9)

El colectivo impulsó de manera autogestionada la publicación de la revista Sitiadas, que, en dos números, dio la palabra a las mujeres internas y externas durante y después de la rebelión. Como dice en el prólogo del primer número:

[...] un rescate de sabidurías distintas, provenientes de mujeres igualmente distintas. Es la voz de las que siempre hemos estado obligadas a callar, es la verdad de muchas, es un espacio de denuncia que busca romper el silencio y tomarnos la palabra, sin pedir permiso, sin pedir perdón, sin esperar que nos la den. (Mujeres de Frente, 2004)

En la investigación de Aguirre en la cárcel de mujeres de El Inca, se indaga sobre lo que implica la cárcel para ellas, sus historias, sus cuerpos, los afectos, los proyectos vitales, las represiones, las violencias y las resistencias. Escrita con fuerza y dolor compartido, con y en compañía de las presas y del colectivo Mujeres de Frente, se nos muestran, por un lado, los efectos y las vivencias del encierro, "que recrea, de modo comprimido, la violencia social del afuera, de castas, racista, capitalista, de clases, individualizante, patriarcal, sexista, agresor, 
voraz, egoísta, intransparente, cínico» (2010: 28) y, por otro, las experiencias de las mujeres encarceladas:

[...] que continúan historias de pueblos y barrios surgidos de la expropiación y la acumulación de los recursos materiales y de expresión por los sectores dominantes, se cuentan entre las que continúan historias repetidas de maternidades tempranas, golpes racistas, criminalización de su empobrecimiento, en esta época en la que a la vulnerabilidad social se la considera antisocial, peligrosa, delincuencial, si se descentra del esquema del «buen pobre». (Aguirre, 2010: 18)

Como ya comenta la propia Lisset Coba, su último libro, SitiadAs: La criminalización de LAs pobres en Ecuador durante el neoliberalismo (sic, las mayúsculas son de Coba), debe su título a la revista Sitiadas, elaborada por sus compañeras de Mujeres de Frente, con quienes compartió la praxis feminista y las historias de vida de las presas (2015: 7). En consonancia con el enfoque crítico, feminista y activista de la revista, la antropóloga vuelve a profundizar en esta investigación en las historias de las mujeres encerradas en El Inca en un estudio etnográfico y de reflexión teórica feminista a partir de tres escenarios de análisis (Coba, 2015: 32):

a) El juzgamiento de las mujeres en los tribunales penales de Pichincha.

b) Las memorias de ilegalidad en las calles de Quito.

c) La cotidianidad en la cárcel de mujeres de Quito.

Coba pretende desarrollar un doble objetivo: una «antropología de la injusticia social en los márgenes del Estado que busca registrar las memorias de los oprimidos y una crítica feminista a la justicia penal, aprisionada en patrones de conducta que legitiman el orden instituido» (Coba, 2015: 6).

La cárcel de El Inca ya no existe, porque la última política del gobierno de Correa de construir nuevos penales regionales más seguros y modernos hizo que se trasladaran, a fines del 2014 , a sus casi 500 mujeres presas, no sin manifestaciones y quejas de familiares y del colectivo feminista, a cárceles alejadas de la capital, en Guayaquil y Cotopaxi (Latacunga). Estas nuevas cárceles de «alta seguridad y control» pueden comportar todavía más exclusión y desarraigo. Como bien comenta Andrea Aguirre en el prólogo al libro de Coba, no tienen nada que ver con El Inca, que:

[...] es una cárcel propia del sistema penitenciario ecuatoriano, abandonado por las más altas autoridades del Estado a la autogestión de la pena y, por eso mismo, permeable a las redes de cooperación social de las personas presas, y a los más diversos empeños de autogestión de comerciantes autónomas, callejeras y penitenciarias. (Coba, 2015: XVI)

Coba analiza estas redes de cooperación, también la «cotidianidad de la subsistencia" y cómo la ley no encarcela solo a las mujeres, sino que también atrapa a redes familiares enteras, porque son ellas las responsables de las mismas antes de entrar en prisión y también durante el encarcelamiento. 
Sin embargo, a pesar de sus atavismos, las relaciones amorosas y las subjetividades del cuidado emergen como posibilidad de resistencia ante los intentos carcelarios de individuación. La opresión heterosexual, las rebeldías lésbicas, las maternidades mistificadas y expropiadas coexisten y conforman una subjetividad melancólica, guiada por el trauma que se alimenta del continuum calle-cárcel-calle, pues la prisión no es un todo autocontenido, sino el sitio de reensamblaje de la cadena de emergencias que constituyen la exclusión. (Coba, 2015: 34)

También acerca de diversas acciones de fuerza y resistencia, como huelgas de hambre, brazos caídos, motines o rebeliones en la cotidianidad y con el vínculo de las otras, se escribe en la compilación de diversos trabajos en Argentina. Analizando los distintos aspectos de vida carcelaria, se han realizado los trabajos de Nari y Fabre (2000), los estudios sociojurídicos de Daroqui y sus colegas (2006) y la investigación desde un enfoque de género y derechos humanos del CELS (2011), que toma como antecedentes a los dos trabajos anteriores. En conjunto, denuncian con datos y argumentos las precarias condiciones de vida de las cárceles estudiadas. Son imprescindibles para conocer la realidad penitenciaria de las mujeres encarceladas en los centros federales de Argentina (no se encuentran estudios sobre las cárceles provinciales). Combinan datos cuantitativos (cifras generales de encarcelamiento, datos por prisión y datos sociodemográficos de las mujeres encarceladas) que hacen la radiografía de la situación, con abordajes cualitativos (entrevistas y cuestionarios) que permiten ir dando la voz a las mujeres presas. Denuncian las condiciones de vida en las cárceles federales de mujeres, sobretodo de la unidad 3 del penal femenino de Ezeiza, con casi 500 internas, criticando lo que ya es habitual en estos estudios sobre cárceles de mujeres: entre otras cuestiones, el hacinamiento y la sobrepoblación; la precariedad de las condiciones habitacionales, de salubridad e higiene de la mayoría de las cárceles, por el deterioro general de las condiciones edilicias a causa de la antigüedad o de la falta de conservación; los servicios médicos del todo insuficientes, con escasa atención a la salud de las mujeres, con restricciones alimentarias y de productos de primera necesidad y excesiva prescripción de psicofármacos; el aislamiento como forma de controlar los conflictos y los abusos de las autoridades; la violencia como una realidad cotidiana, sistemática y en ascenso ejercida por parte de los agentes estatales; la escasez de visitas y de contactos con el exterior; la capacitación laboral prácticamente inexistente y estereotipada con clara orientación "femenino-domestica» en los talleres productivos; el escaso número de profesionales de los equipos técnicos y/o de tratamiento, frente a casi un agente penitenciario por mujer presa (en el caso de las cárceles federales de Argentina), y la falta de asistencia jurídica por parte de los defensores oficiales y particulares (Daroqui et al., 2006; CELS, 2011). Lo que sí se cumple en el penal de mujeres de Ezeiza en Buenos Aires es lo que se cumple en todas las cárceles del mundo, y no solo de mujeres: el orden y la disciplina internos. Ese es el criterio organizativo de la vida de la institución — no la reinserción o la rehabilitación- a través del tratamiento que marca la normativa. Es más, el tratamiento conductual, instrumentado 
mediante un sistema premial-punitivo, se convierte en una herramienta para sustentar la disciplina interna. Al final, como bien dice Mosconi en el prólogo, «la única lógica que parece prevalecer es aquella de la aflictividad punitiva de la pena» (Daroqui et al., 2006: 11). Y por ello emerge, continuando con su argumentación, uno de les temas clave de la penología y, en general, de la cárcel: la fractura entre la pretendida eficacia del derecho y los efectos contradictorios y deformantes de la realidad carcelaria; la constatación de la distancia entre el derecho y la realidad; la diversificación entre las razones declaradas y la funciones reales de la pena. En el mismo sentido, se señala también en el estudio del CELS:

[...] la brecha insalvable entre la vida en prisión y la normativa que la regula [...], la diferencia significativa entre el deber ser mencionado y la realidad observada en los penales de mujeres, y se ponen de manifiesto los obstáculos que ellas deben sortear para ejercer sus derechos fundamentales. (CELS, 2011: 65)

Esa es la diferencia. Las mujeres penadas deben superar muchos más obstáculos que los hombres, como también constata el estudio del CELS, que tiene entre unos de sus objetivos, precisamente, demostrar esta "sobrevulneración» de los derechos de las mujeres encarceladas.

En cuanto a las resistencias, en el libro de las dos argentinas Marcela Nari y Andrea Fabre (2000), se afirma:

[...] en el día a día, en la imperiosa necesidad de reconstruir una cotidianeidad, quizá la estrategia de resistencia más fuerte dentro de la cárcel sea amar. Amar a una pareja, amar a una hija, amar a una madre, amar a un padre, amar a una hermana. No importa que no lo sean, no importa que el vínculo dure lo que dura el encierro. (Nari y Fabre, 2000: 17)

Recitando a Blas de Otero, «[...] me queda la palabra [...]», como título de su contribución, la investigación de Nari y Fabre, junto a otras colegas de su equipo de trabajo interdisciplinario, da la palabra a las mujeres presas en la Unidad 3 del penal de Ezeiza (Instituto Correccional de Mujeres que es la cárcel federal femenina más importante de Argentina). Con las voces de ellas, el trabajo va reflexionando sobre el encierro carcelario femenino. Los efectos sobre las experiencias y las subjetividades de las presas y sus formas de supervivencia y resistencia durante ese tiempo muerto, quieto, el de la espera, el que no pasa, y en donde las relaciones amorosas entre mujeres son reivindicadas, y permiten reformular las vivencias de los tiempos muertos, como también Aguirre (2010) recogía. No están exentas de conflictos y las autoridades ponen trabas y ejercen sus prejuicios, pero escapan más a su control por la propia dinámica de la cárcel (Nari et al., 2000: 47). La cuestión es buscar estrategias de reformulación del tiempo inacabable del encierro, las que sean, con actividades, con trabajos, participando en oficios religiosos aunque no se profese la fe... Y también estrategias de resistencia con medidas de fuerza, como los motines, las huelgas u otras formas más aceptadas por todas y menos castiga- 
das, como utilizar los intersticios institucionales para hacer oír su voz, como la radio, las entrevistas u otro medios para manifestar sus peticiones y demandas. De alguna manera, todas son resistencias al tiempo de castigo que impone la cárcel, «oposición consciente a la infantilización y a la cosificación a la que permanentemente están sometidas" (Nari et al., 2000: 60).

\section{Abordajes institucionales para mejorar las condiciones de vida de mujeres privadas de libertad}

El silenciamiento y la indiferencia social son formas de violencia que deben revertirse si se quiere realmente encontrar una salida que no pase por cristalizarlas en la culpa y perpetuarlas en una condena de marginación y exclusión social.

Marcela Nari y Andrea Fabre, 2000

Sobre la base de esta producción científica y del accionamiento constante de los movimientos sociales de los derechos humanos y el activismo feminista (que les preceden cronológica y epistemológicamente), comenzaron a proliferar, en los últimos años, varios trabajos institucionales, en forma de estudios, informes o protocolos de actuación sobre las mujeres privadas de libertad. En general, están destinados a visibilizar las formas de violencia social e institucional del androcentrismo, a sensibilizar sobre la realidad de las cárceles femeninas en América Latina y a instrumentar mecanismos eficaces para denunciar y/o proteger a estas mujeres ante la vulneración de sus derechos.

La labor de dichos órganos también debe encuadrarse en los movimientos precursores o posteriores a la adopción de dos documentos jurídico-normativos clave: las Reglas de Brasilia, sobre acceso a la justicia de las personas en condición de vulnerabilidad (XIV Cumbre Judicial Iberoamericana, 2008) y las Reglas de Bangkok, de Naciones Unidas para el tratamiento de las reclusas y para las medidas no privativas de libertad para las mujeres delincuentes (UNODC, 2011). De estos dos documentos, se desprende la necesidad de formular y justificar la política penitenciaria y la defensa penal de las mujeres encarceladas, desde una perspectiva de género. En esa dirección, debe conocerse como trabajo específico para América Latina, la realización del Manual Regional: Las Reglas de Bangkok en clave de defensa pública, de Miranda y Martínez (2015). En él, se incluye un análisis de cada de una las 70 reglas que tratan de garantizar el principio de igualdad y no discriminación en el ámbito penitenciario, y se apuntan buenas prácticas en diferentes países latinoamericanos, así como estrategias para trabajar por el cumplimiento de las mismas por parte de las defensas públicas.

Las reglas están teniendo mucho impacto en todos los países, ya que disponen lineamientos para el tratamiento de las reclusas y medidas alternativas al encarcelamiento de mujeres infractoras a la ley penal. Los gobiernos y también algunas investigadoras las han comenzado a analizar con detenimiento. Por ejemplo, así lo hace la argentina Eva María Dorigo (2013), concretamente, en 
el marco del sistema penitenciario peruano y para la Defensoría del Pueblo. Y en este mismo monográfico hay un artículo específico sobre el tema que, desde esa misma perspectiva de género, las analiza muy críticamente.

En ese contexto, y entre otros igualmente relevantes, destacaremos aquí los trabajos de la Comisión de Derechos Humanos de México, el Instituto Latinoamericano de las Naciones Unidas para la Prevención del Delito y el Tratamiento del Delincuente (ILANUD), la Oficina del Alto Comisionado de las Naciones Unidas para los Derechos Humanos (OACDH), el Comité de América Latina y el Caribe para la Defensa de los Derechos de la Mujer (CLADEM), la Oficina Regional de las Naciones Unidas contra la Droga y el Delito para Centroamérica y el Caribe con asiento en Panamá (UNODC ROPAN), el programa EUROsociAl de la Unión Europea y la Conferencia de Ministros de Justicia de los países iberoamericanos-COMJIB.

El informe de la Comisión de Derechos Humanos del Distrito Federal de México es producto de un seminario taller organizado en el año 2003 en la capital mexicana titulado «Violencia contra las mujeres privadas de libertad en América Latina». En esa ocasión, se debatió con expertos de México, Brasil, Colombia, Perú, Costa Rica, Guatemala, Bolivia y representantes de varias instituciones y organizaciones. En las conclusiones del informe, queda del todo constatado que las condiciones en que se encuentran las mujeres privadas de libertad en América Latina no cumplen con los estándares internacionales ni con las normas vigentes para la protección de los derechos humanos y la dignidad personal. El informe de la Comisión focaliza en dos contextos y espacios donde se manifiesta la violencia hacia las mujeres privadas de libertad: las condiciones femeninas en centros de detención y las prácticas discriminatorias contra las reclusas en cárceles (Comisión de Derechos Humanos del Distrito federal et al., 2004). Entre las investigaciones presentadas - base del informe-- destaca la de la uruguaya María Noel Rodríguez (2004), muy útil e interesante, porque muestra una panorámica general de la situación en 18 países de América Latina y analiza algunas cuestiones que todavía no se han estudiado lo suficiente: el uso excesivo e innecesario de la prisión preventiva en el caso de las mujeres, que en muchos casos es de un $40 \%$ más respecto a la de los hombres; las diversas situaciones de violencia contra ellas en los centros de detención y en las cárceles de muchos países que no son informadas — ni cifradas-, y la presencia de personal masculino que labora en los centros de detención femeninos en actividades no previstas o prohibidas por la legislación aplicable. Todo ello genera una falta generalizada - o una ausencia total- de cifras adecuadas sobre tasas femeninas de encarcelación, menores en centros penitenciarios y número de mujeres en instalaciones policíacas. Se impide así, según la investigadora, desarrollar políticas adecuadas y de control de los abusos policiales y/o de los agentes estatales presentes en las cárceles. Mientras aumenta el número potencial de abusos, la sociedad, por otro lado, reclama más seguridad y lucha contra la delincuencia, incentivando la demagogia legislativa con la aprobación de leyes que endurecen todavía más las penas aplicables y las políticas criminales excluyentes. 
El ILANUD tiene, entre sus áreas de acción, la de Género y Justicia Penal. Se trata de un programa dirigido por Alda Facio, la jurista y criminóloga feminista costarricense. De todas las publicaciones, actividades e investigaciones que impulsa sobre el tema, destacamos aquí los estudios efectuados sobre la situación de los menores de edad que viven con sus madres en prisión, como el trabajo efectuado - junto a otras entidades - en las cárceles ecuatorianas (ILANUD et al., 1998). También cabe mencionar el practicado sobre la situación de las mujeres madres y sus hijas e hijos menores de edad en el marco de la privación de libertad femenina en América Central (Costa Rica, El Salvador, Guatemala, Nicaragua y Honduras); trabajo realizado conjuntamente con la Oficina del Alto Comisionado de las Naciones Unidas para los Derechos Humanos (OACDH) y con la citada María Noel Rodríguez como investigadora principal. El propósito de este estudio fue examinar el cumplimiento de la normativa nacional e internacional aplicable, especialmente en materia de derechos humanos, para establecer vínculos entre autoridades penitenciarias, judiciales, organismos de protección a los derechos humanos y oficinas del PNUD en cada país, y con ello poder mejorar la situación de las mujeres privadas de libertad (Rodríguez, 2005: 7).

En la misma línea, es interesante también rescatar el trabajo de la investigadora y asesora de organismos internacionales, Dorigo. Uno de sus estudios trata sobre la situación de las mujeres encarceladas gestantes y/o madres con hijos e hijas menores de tres años en el penal de Chorrillos I, Perú (Dorigo, 2012). Allí se analizan críticamente las áreas de salud, educación, trabajo, servicios de psicología y trabajo social, alimentación e infraestructura, así como las amplias brechas que en ellas existen entre la realidad jurídico-normativa (legislación nacional e internacional) y la realidad social de la ejecución penal y penitenciaria femenina.

Un aspecto que se destaca especialmente en estos y otros estudios que hemos ido nombrando es el elevado porcentaje de mujeres presas que son únicas responsables de sus familias, sean monoparentales o verdaderas redes intergeneracionales muy feminizadas de grupos de crianza y supervivencia normalmente numerosos, de las que son básicamente las principales sustentadoras económicas. Así, su reclusión «encarcelará» también a toda la prole que depende de ella, de modo que en algunos casos de niños y niñas en su primera infancia se llega a la literalidad de la expresión: son físicamente encarcelados con ellas.

Por otro lado, Olga Espinoza, la investigadora brasileña y abogada del ILANUD/Brasil, ha hecho uno de los trabajos a destacar en ese país, el cual, publicado en 2004, recoge para Brasil prácticamente las mismas problemáticas que hemos ido comentando para otros países. Este acompañamiento del ILANUD/Brasil es sumamente relevante, ya que el estudio sobre las cárceles femeninas en Brasil no muestra el mismo desarrollo que en otros países de América Latina; al contrario, es uno de los lugares del que prácticamente no se han documentado estudios. No obstante, sí hay investigaciones e investigadoras de este ámbito desde una perspectiva feminista en épocas mucho más recientes. 
Es el caso de María Palma Wolff, que tiene otro de los libros pioneros para este país (Wolff, 2007), cuyas conclusiones están en total sintonía con lo que hemos ido explicando acerca de otras autoras sobre esta temática (ver también Wolff y Berbich, 2010).

El CLADEM ha realizado un destacado trabajo para Argentina, Brasil, Colombia, Chile, Paraguay y Uruguay, con siete estudios sobre las mujeres privadas de libertad (seis abordan la realidad nacional en la materia y el séptimo sistematiza toda la información regional). Con el apoyo del Instituto de la Mujer del gobierno de España, efectuaron una publicación donde describen las principales temáticas de la vida de las mujeres privadas de la libertad: acceso a la justicia, con especial atención al derecho a la defensa, a los derechos sexuales y a los derechos reproductivos y a la salud integral; situaciones de discriminación y violencia en las cárceles, y tipo de actividades educativas, laborales y programas de resocialización. En los trabajos de ámbito nacional — que constituyen una buena aproximación a la temática para cada país-, se denuncian también, entre otras cuestiones, la falta de acceso a la justicia, la violencia contra las mujeres privadas de la libertad y las duras situaciones que enfrentan estas mujeres en la mayoría de cárceles de estos países (CLADEM, 2008).

Hay otro estudio destacable, en el que se describen las problemáticas y las necesidades de las mujeres encarceladas en Panamá. El mismo ha sido implementado por UNODC-ROPAN bajo el liderazgo de la investigadora Eugenia Rodríguez Blanco (2015), con financiamiento de la Unión Europea en el marco del Proyecto de Cooperación en Seguridad con Panamá (SECOPA).

La COMJIB tiene un importante rol como organización de referencia para la promoción de políticas públicas en materia de justicia. Hasta la fecha, 12 de los 21 países de la región han ratificado el tratado constitutivo, que entró en vigor en septiembre de 1998. La COMJIB ha desarrollado líneas de trabajo relativas a procesos para la reforma de la justicia, el acceso a la justicia, las nuevas tecnologías, la violencia de género, la delincuencia organizada transnacional y la cooperación jurídica internacional. En ese contexto, en abril de 2013, se celebró la XVIII Conferencia en Viña del Mar (Chile), en la que se aprobaron, en el ámbito de la reforma de los sistemas penitenciarios, el Programa Modelo de Género en Contexto de Privación de Libertad para Iberoamérica. El mismo fue diseñado desde la Secretaría General de la Conferencia por mandato expreso de los ministros de Justicia. Fue elaborado fundamentalmente durante las reuniones de expertos penitenciarios de los distintos países que componen el COMJIB llevadas a cabo entre 2011 y 2013, y mantiene la línea de la experiencia o del modelo sugerido por Argentina, que, a la vez, fue profundizado con distintas experiencias regionales aportadas por los asistentes a esas reuniones. Contempla, entre otros muchos aspectos, los desiderátums de cambio y mejora de las condiciones de vida de las mujeres en contextos de encierro, en temas de salud, educación, trabajo, mantenimiento de lazos familiares, derechos humanos, extranjería, pueblos originarios, violencia, etc. (COMJIB, 2013).

También en la XIX reunión plenaria de la COMJIB realizada en Santo Domingo (República Dominicana) en el año 2015, se aprobaron una serie 
de acuerdos y herramientas jurídicas entre las que destacan, en lo que aquí interesa, las «Normas generales para la inserción sociolaboral de las mujeres privadas de libertad y liberadas» (COMJIB, 2015), que fueron propuestas como parte de los documentos de la línea de inserción sociolaboral de las personas privadas de libertad del Programa EUROsociAl.

Este es un programa regional de cooperación técnica de la Comisión Europea para la promoción de la cohesión social en América Latina. En el marco del EUROsociAl II, a lo largo de los últimos dos años, se han desarrollado para diversos países de América Latina distintos protocolos de actuación en el área de la administración de justicia para la atención de los derechos de las mujeres privadas de libertad. Así, en el año 2015, se publicaron los de Nicaragua (específico sobre el marco jurídico y el abordaje institucional), Ecuador (mujeres nacionales y extranjeras privadas de libertad), Chile (específico sobre indígenas extranjeras) y, en 2014, los de Costa Rica (específico sobre mujeres en situación de vulnerabilidad y riesgo social), Perú (específico sobre mujeres extranjeras) y Guatemala (específico sobre el proceso de separación de hijos de madres privadas de libertad). En todos estos protocolos e informes, se debe prestar una atención especial, y es un requisito de obligado cumplimiento, a la perspectiva de género (Almeda y Ballesteros, 2015). Cada documento tiene sus propios consultoras y consultores, quienes, junto a las instituciones de los países implicados — mayormente las defensorías públicas en materia penal-, coordinan una metodología de investigación basada en un diagnóstico de la realidad penitenciaria y, en su caso, una serie de medidas para fortalecer las defensorías públicas de estos países y mejorar la situación y las condiciones de vida de las mujeres privadas de libertad mediante el ejercicio de sus derechos fundamentales.

En conjunto, todos estos trabajos desarrollan estudios comparados en distintos países de América Latina o estudios de caso en países determinados, que, en cumplimiento de la normativa internacional, incluyen y/o proponen una perspectiva de género en sus enfoques. Tienen el mérito de poner de relieve - con las particularidades detectadas en cada sitio- las similitudes y las características comunes de todos los sistemas de justicia criminal de la región, así como de los abordajes propuestos para asumir la realidad de las mujeres en conflicto con la ley penal, especialmente en lo referente a las políticas penitenciarias y a las situaciones femeninas en las cárceles latinoamericanas.

Sería prematuro cualquier valoración sobre lo que están haciendo los gobiernos de todos estos países de América Latina con estos estudios, informes y protocolos. Cabe observar primero si realmente se implementarán las respectivas recomendaciones y evaluar después su impacto. Y hacerlo con precaución, sin ingenuidad ni voluntarismo. Porque aun siendo producciones institucionales, tienen la impronta propia de sus autoras intelectuales; han sido encargados a investigadoras — muchas de ellas también académicas - por parte de entidades de derechos humanos o de organismos nacionales o internacionales que, de una u otra manera, están relacionados con este ámbito, pero que no deciden sobre la ejecución penal femenina ni sobre los aspectos sobre 
los cuales informan, ni dan certeza sobre el compromiso que asumen sus destinatarios directos e indirectos respecto de sus recomendaciones. En cualquier caso, para algo tangible tiene que ser que todas estas instituciones nacionales e internacionales han invertido y apostado tanto. No puede ser en vano que haga más de treinta años que las investigadoras críticas y feministas latinoamericanas vengan estudiando, fundamentando, escribiendo y reclamando a esos gobiernos transformaciones reales en el sistema de justicia criminal de mujeres, y mucho menos cuando algunas de ellas se han implicado tan decididamente en los intersticios del sistema institucional en procura de ejercer una influencia determinante para con las mejores condiciones de vida de las mujeres privadas de libertad.

Deberá estarse alerta, entonces, para que estas actuaciones no sean, una vez más, utilizadas para maquillar la inacción o encriptar la pura acción punitivorepresiva del estado sobre uno de los colectivos de mujeres más vulnerables a los cierres sociales de control y exclusión. Si ello se evita, contribuirían entonces sí- a la expansión orgánica y a la visibilización institucional de esta acuciante realidad, base para instrumentar cualquier transformación política y social sobre la temática.

\section{Conclusiones}

En la actual fase de desarrollo del capitalismo global, el castigo y el control punitivo a las mujeres también se conforma a partir de sus dinámicas centroperiferia, relegando a las peores condiciones de vida y encierro a las habitantes de América Latina que están en conflicto con la ley penal. En este continente con tanta desigualdad social, se reproduce en las cárceles con mujeres la lógica excluyente y opresora del sistema patriarcal de los márgenes. Es decir, se vislumbra con más fuerza que en las prisiones europeas. En Latinoamérica, toda cárcel es más descarnada, precaria, empobrecida y dolorosa. Pero también no tan fragmentaria, individualista, desvinculada - aunque el desvínculo sea siempre alentado por el sistema penitenciario—; más abierta e incompleta institucionalmente, por las propias dinámicas comunitarias y las resignificaciones de las viejas estrategias de supervivencia y bienestar muy desarrolladas en toda América Latina. Por eso mismo, en esta parte del mundo, también vemos emerger, especialmente en algunos países, más posibilidades de acción y resistencia, mayores luchas en contra de esa mayor opresión. La realidad femenina en las cárceles latinoamericanas destapa la olla del sistema de justicia criminal a nivel globalizado, es la punta del iceberg desde donde se reflejan las injusticias y la criminalización de la pobreza femenina a nivel mundial. Y, con ello, las discriminaciones de género, clase y etnia se visualizan cual transparencia, cristalinas, pese a los muros del encierro.

En las cárceles de esta región, se condena la pobreza transgresora de las mujeres latinas, negras, mestizas e indígenas, y también la de sus redes familiares. Ellas son el chivo expiatorio de las políticas antidrogas (de las «drogas» de consumo o uso abusivo prohibido por las autoridades sanitarias; las otras cam- 
pan libremente por las bodegas farmacéuticas y las enfermerías penitenciarias). Por la geopolítica neoliberal que las emplaza, a ellas, las mujeres latinoamericanas, ubicadas en los últimos eslabones de la cadena del narcotráfico, se les confiere condiciones de punición mucho más severas. Las cárceles femeninas en América Latina son una buena atalaya desde donde mirar las nuevas tendencias del control punitivo hacia las mujeres encarceladas por delitos de drogas, las nuevas arbitrariedades y disciplinamientos penales y carcelarios.

En este artículo, las investigadoras, criminólogas, abogadas, educadoras, sociólogas y muchas antropólogas de Argentina, Bolivia, Brasil, Chile, Costa Rica, Ecuador, Guatemala, México, Panamá, Perú, Venezuela u otros países latinoamericanos nos lo explican y lo analizan con lenguajes distintos y miradas diversas, aunque complementarias entre sí. Pero siempre desde enfoques críticos, feministas, interseccionales y situados, con análisis de las distintas variables que tejen las discriminaciones, y ubican la realidad femenina encarcelada en el actual contexto histórico, político, económico, cultural y social latinoamericano.

Cada autora aquí comentada aporta alguna cuestión nueva, añade algún enfoque, una temática no tan tratada, un punto de vista distinto o algunos datos nuevos. A diferencia de los estudios europeos o norteamericanos, las latinoamericanas escriben desde las entrañas, la fuerza y la pasión de un continente maltratado que sigue resistiendo. Ello se refleja en este artículo por el lenguaje y las formas de expresarse de muchas de ellas, por eso las hemos querido transcribir lo más posible. Igual, puede que no sean tan originales; es la rica tradición latinoamericana por la que muchas investigadoras han dado la palabra a las mujeres presas para hablar de ellas, desde ellas.

Como a la realidad que las circunda, demasiado a menudo se las ha olvidado, ninguneado, menospreciado, especialmente por la criminología dominante, pero también por la criminología crítica y feminista, sobretodo anglosajona, que apenas las menciona. En este trabajo, visualizamos la inmensa labor que se ha hecho - $-\mathrm{y}$ se está haciendo-, sistematizando los principales aportes que, desde este continente, se vienen produciendo para la comprensión y superación de las formas más injustas del control punitivo institucionalizado de la mujer.

Son científicas sociales latinoamericanas, compenetradas en su saber comunitario según los particulares devenires de los procesos populares que caracterizan a su región. En este trabajo, ha quedado en evidencia que todo lo que se está produciendo en este vasto continente, especialmente desde principios del siglo XXI, sobre el sistema de justicia criminal y las mujeres, es mucho, profundo y del todo relevante para el conjunto de perspectivas críticas y feministas a nivel internacional.

\section{Referencias bibliográficas}

AcHÁ, Gloria Rose (1998). «Características de las mujeres encarceladas en Bolivia». En: Olmo, Rosa del (coord.). Criminalidad y criminalización de la mujer en la región andina. Caracas: Nueva Sociedad. 
Aguirre Salas, Andrea (2010). Vivir en la fractura: El castigo y las resistencias en la cárcel de mujeres. Quito: Ediciones Abya-Yala / Universidad Andina Simón Bolívar. Magíster, 96.

Almeda Samaranch, Elisabet (2002). Corregir y castigar: El ayer y hoy de las cárceles de mujeres. Barcelona: Ediciones Bellaterra.

Almeda Samaranch, Elisabet y Ballesteros Pena, Ana (2015). Protocolo de atención a mujeres privadas de libertad, nacionales y extranjeras, en Ecuador. Madrid: Programa EUROsociAL.

Almeda Samaranch, Elisabet; Di Nella, Dino y Navarro, Carmen (2012). «Mujeres, cárceles y drogas: Datos y reflexiones». Oñati Socio-Legal Series, 2 (6), 122-145.

Andersen, Margaret y Hill Collins, Patricia (ed.) (1992). Race, Class and Gender: An Anthology. Boston: Cengage Learning, 2013.

Aniyar de Castro, Lola (1976). Criminología de la Reacción Social. Maracaibo: Centro de Investigaciones Criminológicas de la Universidad del Zulia.

- (1986). «La delincuencia femenina en Venezuela: Ideología de la diversidad y marginalidad». En: ANIYAR DE CASTro, Lola (ed.). La realidad contra los mitos: Reflexiones criticas en Criminología. Maracaibo: Publicaciones de la Universidad del Zulia, 2002.

- (2002). «Las mujeres infractoras: Impacto y amplificación de los efectos de la pena». Capitulo Criminológico, 30 (4), 333-351.

Antony García, Carmen (2001). Las mujeres confinadas: Estudio criminológico sobre el rol genérico en la ejecución de la pena en Chile y América Latina. Santiago: Editorial Jurídica de Chile.

- (2007). "Mujeres invisibles: Las cárceles femeninas en América Latina». Nueva Sociedad, 208, 73-85.

Aponte SÁnchez, Elida (2002). «Las mujeres reclusas de la cárcel nacional de Maracaibo». Otras Miradas, 2 (1), 38-49.

Azaola, Elena (1995). «Prisiones para mujeres: Un enfoque de género». La Ventana, 2, 35-52.

- (1996a). El delito de ser mujer. México DF: Plaza y Valdés-Ciesas.

- (1996b). "Les femmes autochtones incarcérées au Mexique». Recherches Amérindiennes au Québec, 26 (3-4), 75-82.

- (1997). «Mujeres sentenciadas por homicidio en la ciudad de México». Papers: Revista de Sociología, 51, 93-102.

- (1998). «Nuevas tendencias en la criminalidad femenina». En: Olmo, Rosa del (coord.). Criminalidad y criminalización de la mujer en la región andina. Caracas: Nueva Sociedad.

- (2002). "Víctimas no visibles del sistema penal». En: Niños y niñas invisibles: Hijos e hijas de mujeres reclusas. México DF: UNICEF-Inmujeres.

- (2005). "Las mujeres en el sistema de justicia penal y la antropología a la que adhiero». Cuadernos de Antropología Social, 22, 11-26.

- (2008). Crimen, castigo y violencias en México. Quito: FLACSO - MDMQ. Ciudadanía y Violencias.

- (2014). "Women Prisoners: Theory and Reality in México». En: Deflem, Mathieu (ed.). Punishment and Incarceration: A Global Perspective, Sociology of Crime, Law and Deviance, 19. Bingley: Emerald Group Publishing.

Azaola, Elena y José YaCAmán, Cristina (1996). Las mujeres olvidadas: Un estudio sobre la situación actual de las cárceles de mujeres en la República Mexicana. México DF: CNDH-Colmex. 
Castillo, Adisea (2008). «Rosa del Olmo: Los problemas de género en su obra». Revista Venezolana de Estudios de la Mujer, 13 (31).

CELS (2011). Mujeres en prisión: Los alcances del castigo. Madrid: Siglo Veintiuno Editores.

CLADEM (2008). Violencia contra mujeres privadas de libertad: Sistematización regional en Argentina, Brasil, Chile, Colombia, Paragua y Uruguay. Lima: CLADEM.

Coba, Lisset (2001). La muerte social: El Centro de Rehabilitación Social Femenino de Quito (CRSFQ) como situación humana. Quito: INREDH-CEE.

- (2004). Motín y amores en la cárcel de El Inca. Quito: Universidad Andina Simón Bolívar. Tesis de maestría.

- (2015). Sitiadas: La criminalización de las pobres en Ecuador durante el neoliberalismo. Quito: FLACSO-Ecuador.

Comisión de Derechos Humanos del Distrito Federal et al. (2004). Violencia contra las mujeres privadas de libertad en América Latina. México DF: Ediciones Corunda.

COMJIB (2013). Programa modelo de género en contexto de privación de libertad para Iberoamérica. Madrid: COMJIB.

- (2015). Normas generales para la inserción socio laboral de las mujeres privadas de libertad y liberadas. Madrid: COMJIB.

Cumbre Judicial Iberoamericana (2008). Reglas de Brasilia sobre acceso a la justicia de las personas en condición de vulnerabilidad. XIV Cumbre Judicial Iberoamericana. Brasilia: Secretaria Permanente.

Daroqui, Alcira et al. (2006). Voces del encierro. Mujeres y jóvenes encarcelados en Argentina: Una investigación socio-jurídica. Buenos Aires: Omar Favale Ediciones Jurídicas.

Davis, Angela (1981). Women, Race and Class. Nueva York: Random House.

Dorado, María Cristina (1998). «Mujeres latinoamericanas detenidas en Europa: El caso de Colombia». En: Olmo, Rosa del. Criminalidad y criminalización de la mujer en la región andina. Caracas: Nueva Sociedad.

Dorigo, María Eva (2012). Detrás del muro, hay madres. Diagnóstico situacional: brechas entre la normativa y la situación penitenciaria de la mujer gestante madre con hijos privadas de libertad en el penal de Mujeres Chorrillos I. Lima: Pontificia Universidad Católica del Perú. Tesis de maestría.

- (2013). Lineamientos para la implementación de las Reglas de Bangkok en el sistema penitenciario peruano. Lima: Defensoría del Pueblo.

Espinoza Mavila, Olga (2004). «Mujeres presas en Brasil: Una aproximación». En: Comisión de Derechos Humanos del Distrito Federal et al. Violencia contra las mujeres privadas de libertad en América Latina. México DF: Ediciones Corunda.

Giacomello, Corina (2013). Mujeres, delitos de drogas y sistemas penitenciarios en América Latina. Londres: IDPC.

Hernández, Rosalva Aída (2013). «Del Estado Multicultural al Estado Penal: Mujeres Indígenas Presas y Criminalización de la Pobreza». En: Sierra, María Teresa et al. (ed.) (2013). Justicias indígenas y Estado: Violencias contemporáneas. México: Flacso, 299-338.

Hill Collins, Patricia (1990). Black Feminist Thought: Knowledge, Consciousness, and the Politics of Empowerment. Londres: Routledge. Versión electrónica, 2000.

ILANUD et al. (1998). Estudio de la situación actual de los niños, niñas y adolescentes, hijos de los privados de libertad de los CRS. Quito: ILANUD, MBS, DNRS, INNFA. 
Lagarde, Marcela (1990). Los cautiverios de las mujeres: Madres, monjas, putas, presas y locas. México DF: Universidad Nacional Autónoma de México, 2005. Posgrado.

Miranda, Manuel y Martínez, Silvia Edith (2015). Manual Regional: Las Reglas de Bangkok en clave de defensa pública. Madrid: Programa EUROsociAL.

Mujeres de Frente (2004). «Un trabajo de mujeres hartas de su situación». Sitiadas, 1.

- (2006). «Un nuevo trabajo de mujeres hartas de su situación». Sitiadas, 2.

NARI, Marcela et al. (2000). «Me queda la palabra: Estrategias de resistencia de mujeres encarceladas». En: NARI, Marcela y Fabre, Andrea (comps.). Voces de mujeres encarceladas. Buenos Aires: Catálogos.

NARI, Marcela y FABre, Andrea (comps.) (2000). Voces de mujeres encarceladas. Buenos Aires: Catálogos.

Olmo, Rosa del (1981). América Latina y su criminología. México DF: Siglo XXI.

- (1987). "Criminología y Derecho Penal: Aspectos Gnoseológicos de una relación necesaria en América Latina». Revista Doctrina Penal, 10 (37), 23-43.

- (1988). «Droga y criminalización de la mujer». Revista Nueva Sociedad, 93,156167.

- (1989). «Drogas: distorsiones y realidades». Revista Nueva Sociedad, 112, 102-114.

- (1991). "La internacionalización jurídica de la droga». Revista Nueva Sociedad, 122, 81-93.

- (1998a). «Reclusión de mujeres por delitos de drogas: Reflexiones iniciales». Revista Española de Drogodependencias, 23, 5-24.

- (coord.) (1998b). Criminalidad y criminalización de la mujer en la región andina. Caracas: Nueva Sociedad.

Organización de las Naciones Unidas (2011). Reglas de las Naciones Unidas para el tratamiento de las reclusas y medidas no privativas de la libertad para las mujeres delincuentes. Reglas de Bangkok. New York: Naciones Unidas.

Palma Campos, Claudia (2011). «Delito y sobrevivencia: Las mujeres que ingresan a la cárcel El Buen Pastor en Costa Rica por tráfico de drogas». Anuario de Estudios Centroamericanos: Universidad de Costa Rica, 37, 245-270.

Ribas, Natalia; Almeda Samaranch, Elisabet y Bodelón, Encarna (2005). Rastreando lo invisible: Mujeres inmigrantes en las cárceles. Barcelona: Anthropos. Migraciones.

Rodríguez, María Noel (2004). «Mujer y cárcel en América Latina». En: Comisión de Derechos Humanos del Distrito Federal et al. Violencia contra las mujeres privadas de libertad en América Latina. México DF: Ediciones Corunda.

- (2005). Mujeres madres en prisión en América Central. San José de Costa Rica: Editorial Universidad Estatal a Distancia.

Rodríguez Blanco, Eugenia (2015). Diagnóstico de la Situación de las Mujeres Privadas de Libertad en Panamá: Desde un enfoque de género y derechos. Panamá: UNODC-SECOPA.

Salazar, Teresa (2007). «Análisis sobre la delincuencia femenina por droga: Centro penitenciario los Andes. Mérida-Venezuela. 2005-2006». Capítulo Criminológico, 35 (4), 539-562.

Torres Angarita, Andreína (2008). Drogas, cárcel y género en Ecuador: La experiencia de mujeres mulas. Quito: FLACSO-Ecuador.

WaCQuAnt, Loïc (2004). Las cárceles de la miseria. Buenos Aires: Manantial.

Wolff, Maria Palma (et al.) (org.) (2007). Mulheres e Prisão: A experiência do Observatório de Direitos Humanos da Penitenciária Feminina Madre Pelletier. Porto Alegre: Dom Quixote. 
Wolff, Maria Palma y Berbich de Moraes, Marcia Elayne (2010). «Mulheres e tráfico de drogas: Uma perspectiva de gênero». Revista Brasileira de Ciencias Criminais, 18 (87), 375-395.

Zaffaroni, Eugenio Raúl (1993). «La mujer y el poder punitivo». En: Vigiladas y castigadas: Seminario Regional de Normatividad Penal y Mujer en América Latina y el Caribe. Lima: CLADEM.

- (2015). "Lolita in Memóriam». En: Lola Aniyar de Castro: La partida de una indispensable [en línea]. Noticias UNSAM-Universidad Nacional de San Martin (11-12-2015). <http://noticias.unsam.edu.ar/2015/12/11/lola-aniyar-de-castrola-partida-de-una-indispensable/>. 